\title{
Aero-Structural Study on the Blade Thickness Effects in an Automotive Turbocharger Turbine in Transonic Conditions
}

\author{
Azadeh SAJEDIN, Mohammad Hasan SHOJAEIFARD, Abolfazl KHALKHALI \\ Iran University of Science and Technology, 1684613114, Resalat Sq., Farjam street, Tehran, Iran, \\ E-mail:ab_khalkhali@iust.ac.ir
}

cross $^{\text {ref }}$ http://dx.doi.org/10.5755/j01.mech.25.2.22151

\section{Nomenclature}

$C_{i s}$ - isentropic flow velocity; $d_{2}$ - rotor mean inlet diameter; $m$ - mass flow; $N$ - speed of rotation; $P R$ - pressure ratio; $W$ - work rate; $M P$ - mass parameter; $T$ - temperature; $\eta$ - efficiency; S.S - suction-side; $P . S$ - pressure side; $C_{p}$ - pressure loading coefficient.

Subscripts-

0 - Stagnation conditions; 1 - Nozzle inlet station; 2 - Rotor inlet station; 3 - Rotor exit station; eff - efficiency; Is - Isentropic process; $O$ - Reference value; $s$ - Static condition; $T-$ Total condition.

\section{Introduction}

Highly loaded turbocharger turbine blades are damaged by alternating stresses resulting from the excitation forces due to inlet charge stroke and unsteady effects of the stator blade in vast operating points of different load and speed [1]. Some recent researcher tried to increase the aero structural performance by blade outlet angle and blade material $[2,3]$. FSI studies get the attention of the several researchers in recent years. Shanechi et al. [4] optimized a 5.7 air pressure ratio single stage radial-inflow turbine applied in the Sundstrand Power Systems T-100 Multipurpose Small Power Unit (MPSPU) by using coupled CFD-FE method. The meridional parameters, tip clearance, and blade thickness distribution were systematically changed to obtain the optimized geometry. Vanti et al. [5] perform an optimization for a three-dimensional blade geometry redesign, taking into account aeroelastic requirements. Their aim was to consider both the aerodynamic and the aeromechanic goals in a multi-objective optimization process to be used during the design phase. Chaochen et al. [6] investigated the forced response mechanisms based on a fluid structure interaction (FSI) method. They found that the maximum dynamic stresses induced by the first two harmonic pressures both are located on the leading edges of the rotor blades. The dynamic stress induced by the first harmonic pressure is considered as the major alternating stress. Wang et al. [7] developed a model based on a one-way coupling of CFD and FEA of a wind turbine. And studied the stresses and deflections. Dai et al. [8] presented a coupled CFD-CSD method for aeroelastic analysis of HAWTs rotor blades and investigated the effects of yaw angle on aerodynamic performance of rotor blades and also the effects of FSI on aerodynamic performance of rotor blades. They found that maximum deflection and stress of rotor blades in yaw conditions increased. Rafiee et al [9] performed a Fluid-structure interaction analysis of a wind turbine blade and determined
Static and dynamic responses of the blade at the important wind speeds. They investigated the effects of aeroelasticity on output power generation. Carrion et al. [10] presented static and dynamic aeroelastic analyses for wind turbines and analyzed the effect of the torsional stiffness on the aerodynamics. The dynamic CFD-CSD method was applied and substantial blade deformations were observed at high wind speeds. Ok Yu et al. [11] presented A coupled CFDCSD method for aeroelastic analyses of HAWT rotor blades and investigated the effects of blade deformation on the rotor blade airfoils. Following related studies in the field $[1,12,13]$, blade deformations are negligible, and aerodynamic forces can be computed with the assumption of a nonvibrating solid structure. So one-way coupling on turbocharger turbine blade could be efficient. For investigating the thickness effects of radial turbocharger turbine blades in this work, a correlation proposed by Aungier was implemented $[14,15]$. The main question of this essay is to illustrate the influence of the blade thickness and its distribution from leading edge to trailing edge on the blade performance and aerostatic behavior of a double entry turbocharger turbine. This is done by a 3D computational model efficiently coupled with FEM model which allows prediction of fluidstructure interactions in turbocharger turbines with stationary turbine inlet conditions. The computational domain consists of a whole turbine which is shown in Fig. 1. Table 1 records some geometry characteristics of the rotor and the nozzle [15].

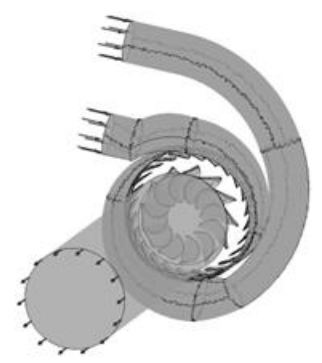

Fig. 1 Computational domain

Table 1

Optional turbine geometry parameters

\begin{tabular}{|l|c|}
\hline Root Mean Radius at Trailing Edge, $\mathrm{mm}$ & 52 \\
\hline Length of Axial Chord, mm & 40 \\
\hline Number of Blades & 12 \\
\hline Inlet cone angle & $55.1^{\circ}$ \\
\hline Exit cone angle & $7.2^{\circ}$ \\
\hline Number of nozzle blades & 24 \\
\hline Nozzle vane angle & 70 \\
\hline Total pressure ratio (Design point) & 2.1 \\
\hline Design rotor speed, rpm & 53344 \\
\hline Nozzle throat diameter & 4.405 \\
\hline
\end{tabular}




\section{Computational analysis}

The computational analysis was performed using the ANSYS CFX V.17 CFD package. The boundary conditions, Pressure (total at inlet and static at outlet) and temperature were taken from measurements from experimental. After validation of the model with profile a, it was applied for the four other blades profile at the design point. Profile "a" was related to a mixed turbine which was tested by Copeland et al. [15]. Profiles e and d have the similar camber line with profile "a" but different thickness distribution. Profile $b$ and $c$ thickness distribution were defined by the direct method proposed by Aungier [14] and some other limitations. In Fig. 2 thicknesses distribution parameters are depicted. Where $t_{\max }$ is the maximum blade thickness, $t_{2}$ is the leading edge blade thicknesses distribution, $t_{2}$ is the trailing edge blade thicknesses distribution and $\mathrm{c}$ is the chord length. Dividing all parameters by chord length leads to generate airfoil thickness in dimensionless form.

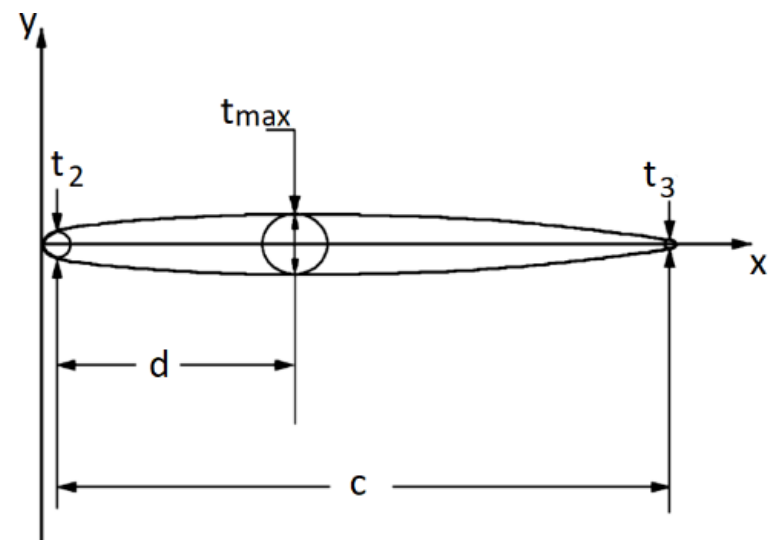

Fig. 2 Blade thickness characteristic [12]

In which:

$$
\begin{aligned}
& t=t_{\text {ref }}+\left[t_{\text {max }}-t_{r e f}\right] \xi^{e}, \\
& t_{\text {ref }}=t_{2}+\left[t_{3}-t_{2}\right]\left(\frac{x}{d}\right),
\end{aligned}
$$

$$
\begin{aligned}
& \xi=\frac{x}{d} ; x \leq d, \\
& \xi=(c-x) /(c-d) ; x>d, \\
& e=\sqrt{0.4 d / c} 0.95\left(1-\frac{x}{c}\right)(1-\xi)+0.05,
\end{aligned}
$$

For airfoil cooling and blockage considerations, stress and tolerance limitation, the trailing-edge thickness should not be less than $0.375 \mathrm{~mm}$ which restricts rotor blade count [16]. The trailing-edge blockage definition is the ratio of the trailing-edge tangential thickness $b$ to the blade or vane spacing $s$ which should be kept less than 0.1 for avoiding performance drop [14]. Where $Z$ is the blade number.

$$
\frac{b}{s}=\frac{t_{3} / \cos \propto_{t e}}{2 \pi r / z}
$$

The blades thickness characteristics and shape of profiles are depicted in Table 2. Fully turbulent flow was assumed because of Reynolds number was calculated as $6 \times 10^{5}$ at the stator inlet. For turbulence modeling the $K-\epsilon$ was used. A whole turbine steady state model which include the double entry volute, stator, rotor and a diffuser was used with a frozen rotor interface between rotational and non-rotational domains [17]. The RMS residual convergence was imposed to $1 \times 10-5$, this is a good convergence by CFX [17], in some cases the convergence was set as low as $1 \times 10-7$. $Y+$ values were obtained lower than 6 . Minimum cell angle of all domains was 15 degrees. A structured mesh was generated for the rotor and stator using TurboGrid-11. In the tip clearance gap at least ten nodes were assumed. Different cell numbers were used to find the most proper mesh density; specification of trials for rotor and stator are depicted in table 3 . Between the imposed grid resolutions, trials 4 and 5 show the least variation in efficiency and mass flow, although, there is a significant difference in their CPU time. So, as a compromise between the accuracy, grid independence and computational cost, mesh size in the fourth row of Table 3 was selected.

Table 2

Profiles thickness characteristics

\begin{tabular}{|c|c|c|c|c|c|c|}
\hline & $d, \mathrm{~mm}$ & $t_{\max }, \mathrm{mm}$ & $t_{2}, \mathrm{~mm}$ & $t_{3}, \mathrm{~mm}$ & Blockage & Trailing edge shape \\
\hline Profile a-original & 9.4 & 2.84 & 0.6 & 0.5 & 0.026 & Cut off \\
\hline Profile b & 10 & 2.8 & 0.8 & 0.375 & 0.017 & Partial cut off \\
\hline Profile c & 15 & 3.6 & 0.8 & 0.375 & 0.017 & rounded \\
\hline Profile d & 9.4 & 2.75 & 0.6 & 0.4 & 0.021 & Cut off \\
\hline Profile e & 9.4 & 3 & 0.65 & 0.5 & 0.026 & Cut off \\
\hline
\end{tabular}

Table 3

Mesh intensity study

\begin{tabular}{|l|l|l|l|l|l|}
\hline Trial & \multicolumn{2}{|c|}{ Number of elements } & Stage total-to-static efficiency, \% & Mass flow rate, $\mathrm{kg} / \mathrm{s}$ & CPU time, hrs. \\
\hline \multirow{3}{*}{1} & \multicolumn{1}{|c|}{ Nozzle } & \multicolumn{1}{|c|}{ Rotor } & & & \\
\cline { 2 - 7 } 2 & 153,545 & 254,354 & 58.35 & 0.495 & 12 \\
3 & 436,565 & 625,873 & 60.86 & 0.502 & 23 \\
4 & 835,463 & $1,135,512$ & 62.09 & 0.506 & 46 \\
5 & $1,465,436$ & $1,825,434$ & 61.55 & 0.505 & 75 \\
\end{tabular}




\section{Comparison between experimental and numerical results}

The results were validated by the experimental measurements of Copeland et al. for both mass flow parameter and efficiency in full admission case [15]. These characteristics with their definition are introduced as:

The corrected mass flow parameter:

$$
M P_{o}=\left(\frac{\dot{m} \sqrt{T_{01}}}{P_{01}}\right)_{0}
$$

The pressure ratio:

$$
P R_{T s}=\frac{\left(P_{\text {total }}\right)_{01}}{P_{\text {static exit }}} .
$$

The velocity ratio:

$$
\frac{U_{3}}{C_{i s}}=\left[\frac{N}{\sqrt{T_{0}}}\right] \frac{\pi d_{2}}{\sqrt{2 C_{p}\left(1-P_{3} / P_{01}\right)^{\frac{\gamma-1}{\gamma}}}} .
$$

The total to static isentropic efficiency:

$$
\eta_{t-s}=\frac{\tau \omega}{\dot{m} C_{p} T_{01}\left(1-P_{3} / P_{01}\right)^{(\gamma-1) / \gamma}} .
$$

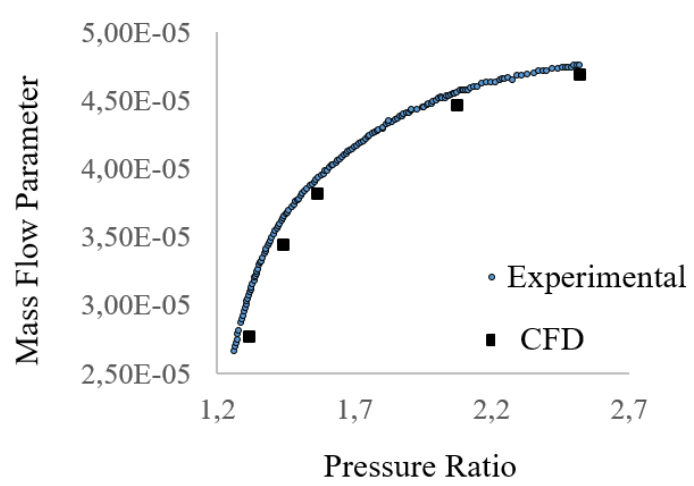

a

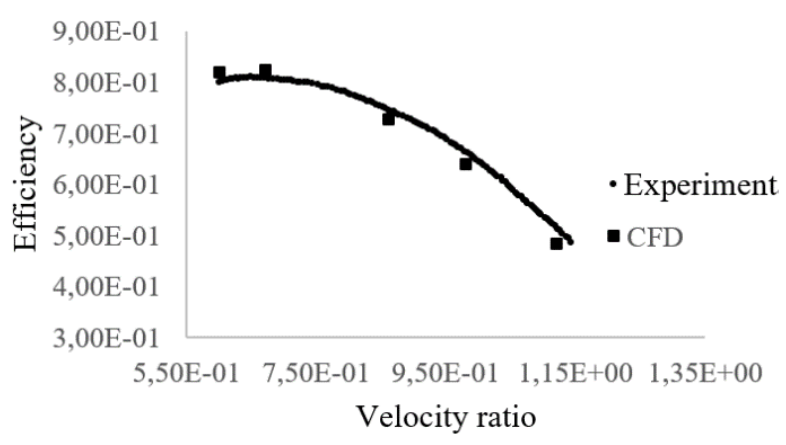

b

Fig. 3 Comparison of (a) computed and measured pressure ratio against mass flowrate(b) computed and measured efficiency against velocity ratio
Fig. 3 shows the comparison between relative mass parameter versus total-to-static pressure ratio and total-tostatic relative efficiency against velocity ratio with experimental data in full admission case. The pressure ratio varied from 1.3 to 2.5 which was equal to velocity ratios ranged from 1.12 to 0.6. Mass flow characteristic of the model coincides the experimental data well. Less than 8 percent discrepancy can be seen at lowest pressure ratio while at higher pressure ratio this is 1 percent. In the lower efficiencies, the enormous uncertainty in the experimental results which can be as high as $\pm 5 \%$, leads to more discrepancy [15].

\section{Results and discussion}

The selected plane for showing the Mach number is shown in Fig. 4, a with yellow color. This plane has constant span in all the blades and is unwrapped in blade to blade view (Fig. 5, I). In Fig. 4 section b the Mach distribution around the blade at equal admission in $53344 \mathrm{rpm}$ and pressure ratio of 2.2 shows a bow shock before the airfoil, where the Mach number is dropped suddenly through it. Also near the trailing edge there is a weak shock which caused another drop in Mach number. Fig. 5 shows velocity vectors at half span and Mach number distribution for the five different blade profiles at pressure ratio of 2.2 and velocity ratio of 0.75 .

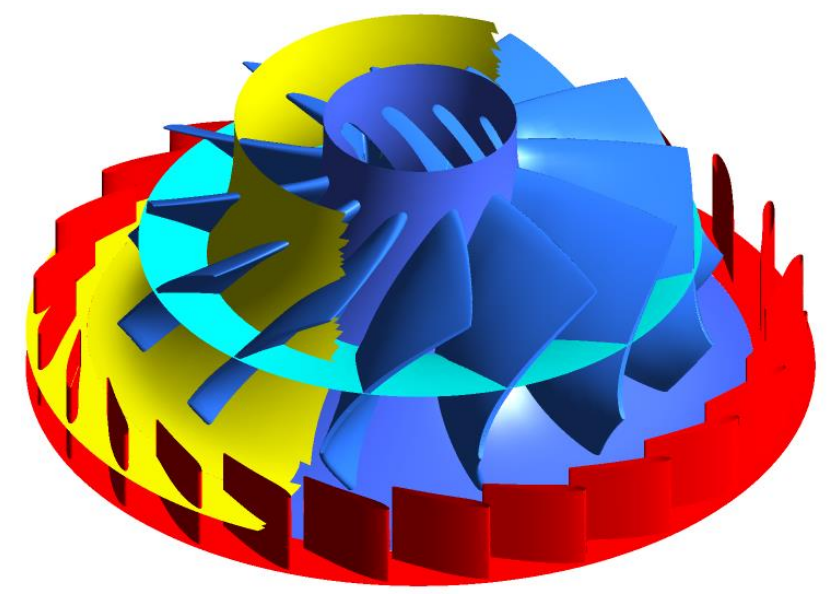

a

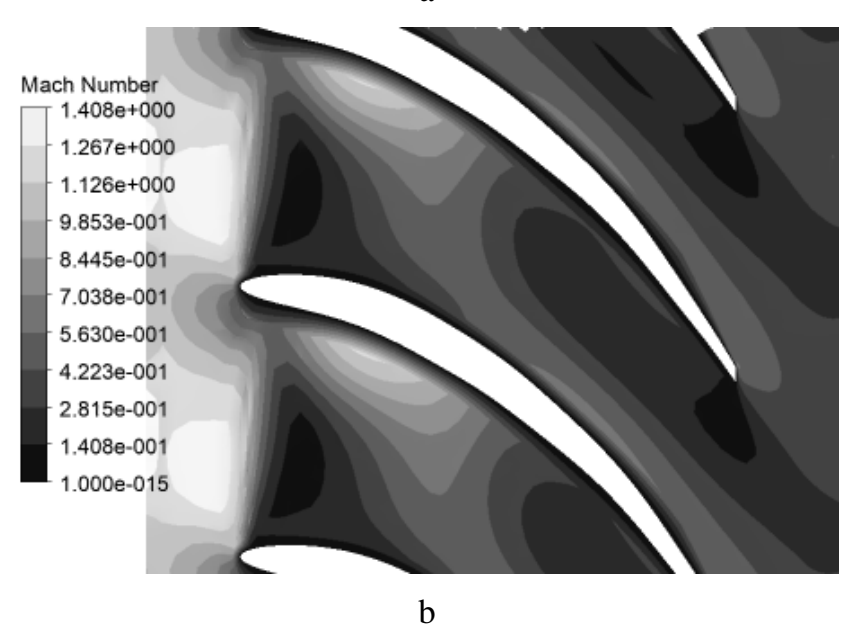

Fig. 4 Selected view plane (a); Mach distribution (b) 


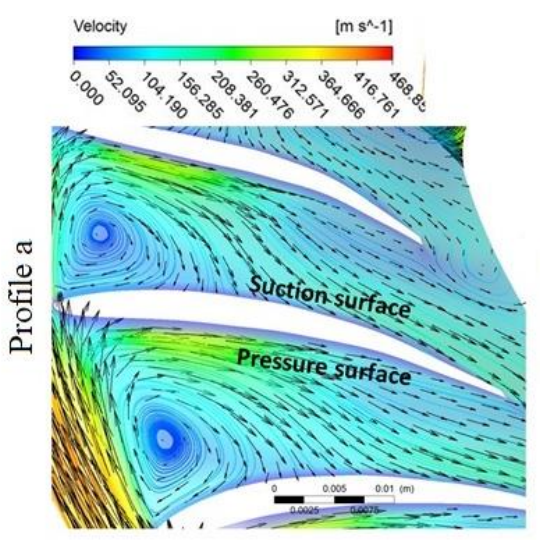

Velocity

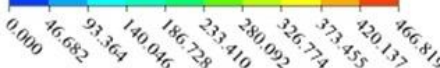

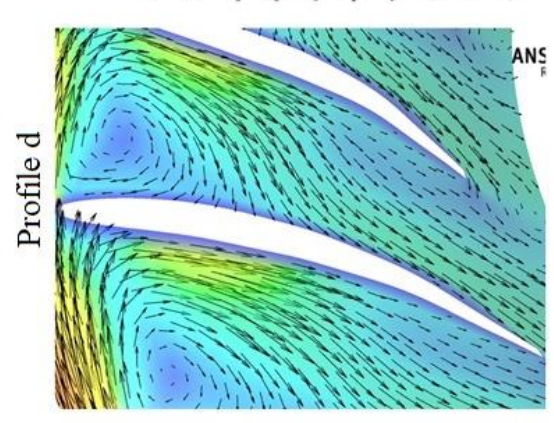

(I)

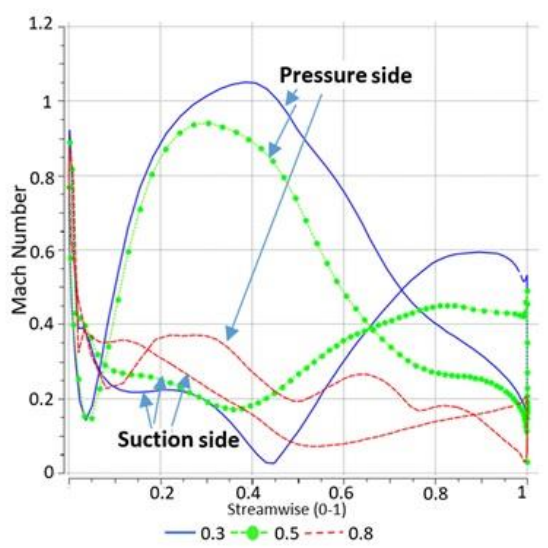

(Profile a)

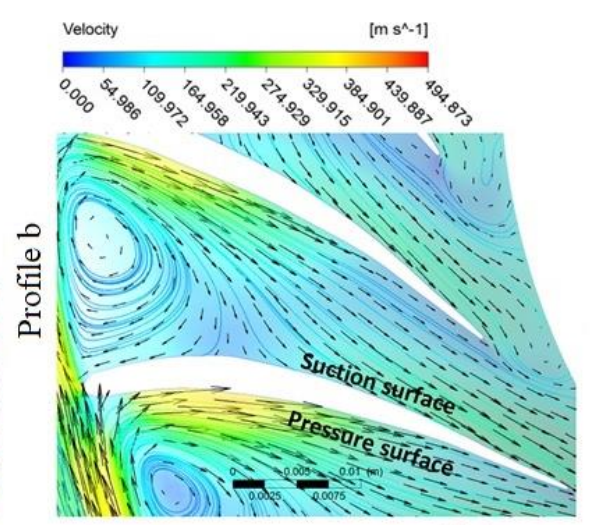

$\left[\mathrm{m} \mathrm{s}^{\wedge}-1\right]$
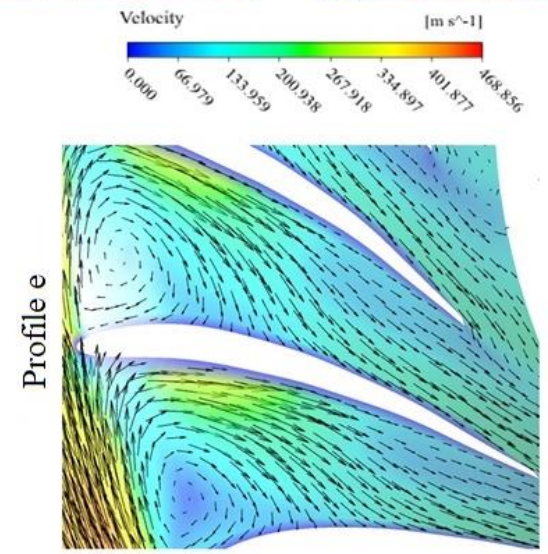

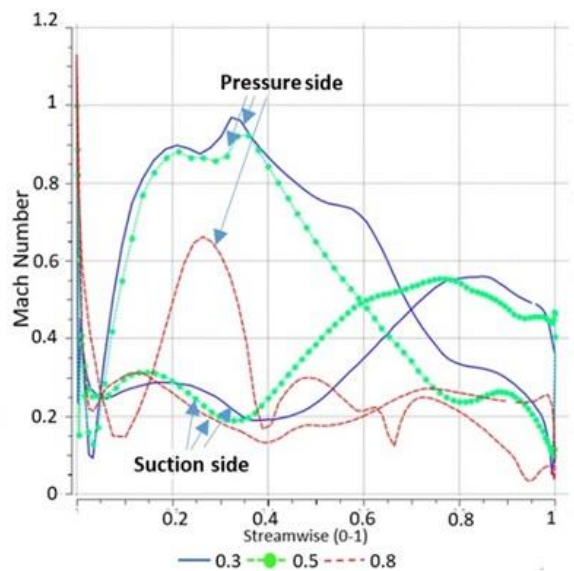

(Profile b)

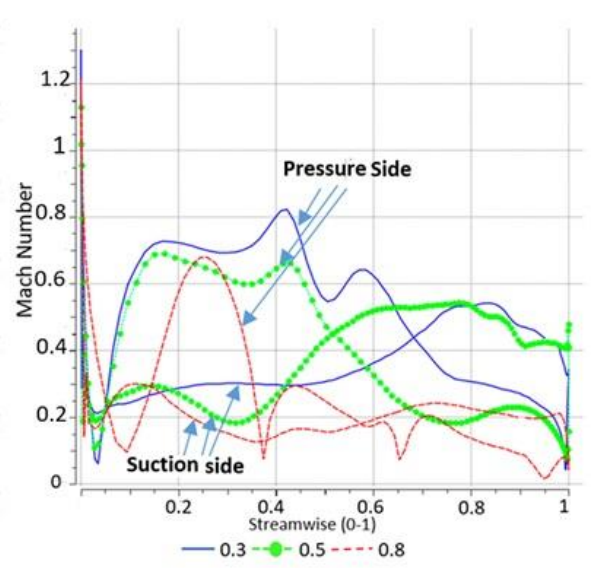

(Profile c)

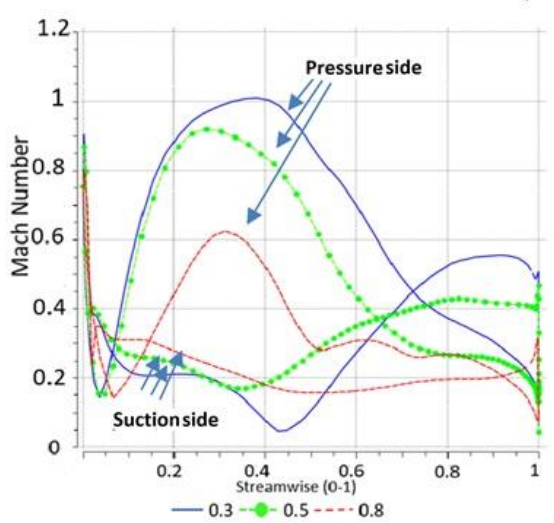

(Profile d)

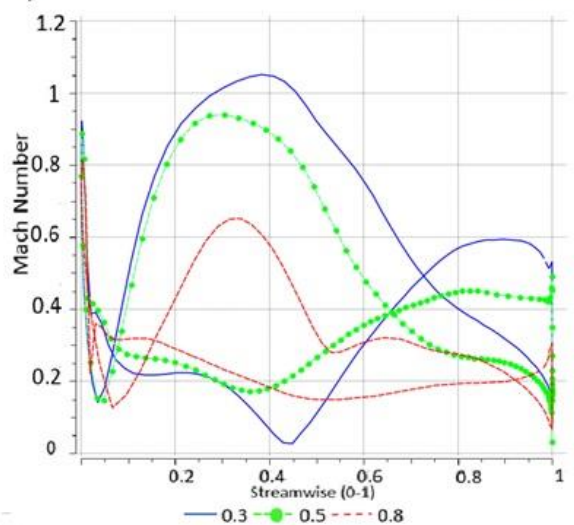

(Profile e)

(II)

Fig. 5 (I) Velocity vectors (II) Mach number distribution of profiles a, b, c, d and e 
On both pressure and suction surfaces shock cause a drop in Mach number and after that on the pressure surface, Mach number is increasing with decreasing the passage area and after reaching to sonic condition at throat, it decreases. At the trailing edge a weak shock is happened which cause another drop in Mach number of pressure surface, also it reflects to the suction surface of the near blade and caused the Mach reduction on suction surface too. On the suction surface after subsonic diffusion in shock region the boundary layer is separated and a separation bubble is formed which is stretched to the throat region. After that the flow accelerate continuously because the fluid velocity increases by interaction with the surrounding high momentum flow. At the trailing edge the Mach number is decreased because of the pre mentioned weak shock of the pressure sur- face of the next blade. In profiles b and c with thicker leading edge the drop in Mach through the bow shock is higher also the separation bubble on the suction surface because of higher $\mathrm{d}$ (the place of maximum thickness) is smaller. Also there are several sharp drop in Mach number on the pressure surface because of small discontinuities on the surface curvature. In all profiles, Mach number in lower spans is higher, and it decreases as moving to higher span layers. The most uniform flow vectors are related to the profiles e and d. Profile "a" and " $d$ " have the highest Mach number among the all. The meridional variations of loaded force on turbine blade are shown in Fig. 6 for each point of the rotor blade. With thickening the leading edge, the loaded force reduced a little but thickening whole the blade significantly decreased the loaded force.

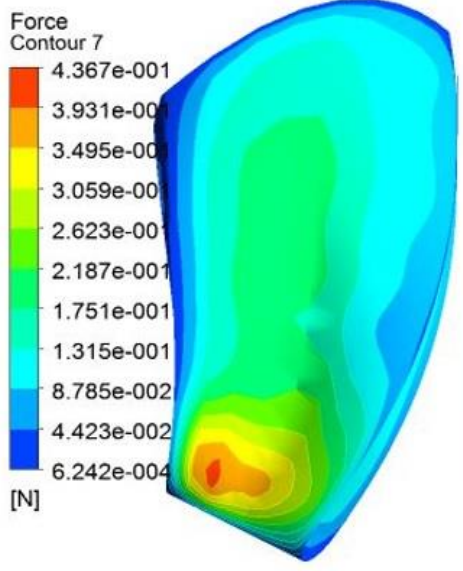

Profile "a"

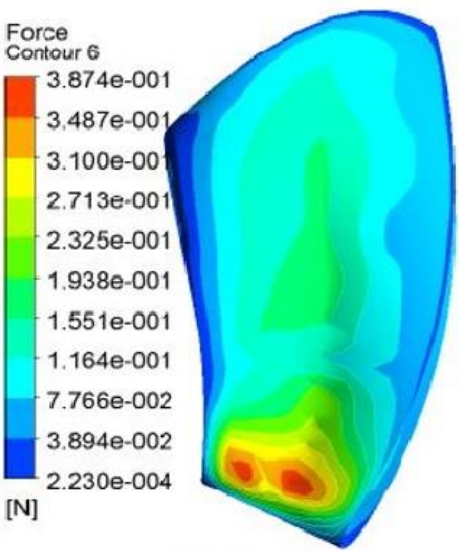

Profile "b"
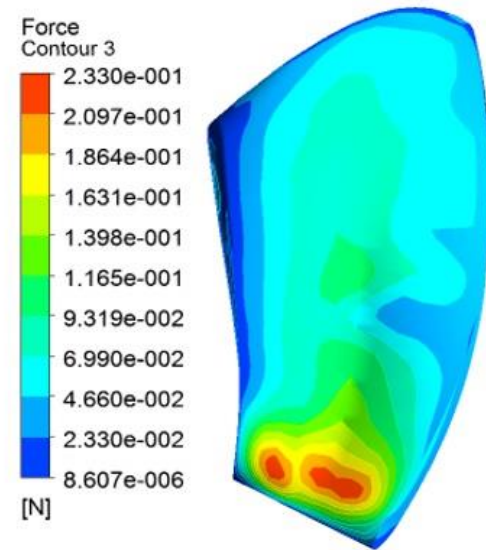

Profile "c"

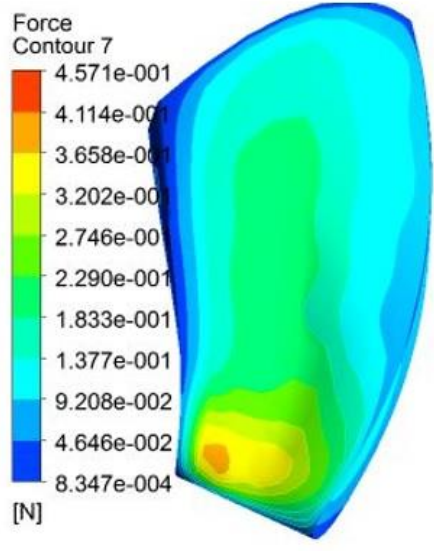

Profile "d"

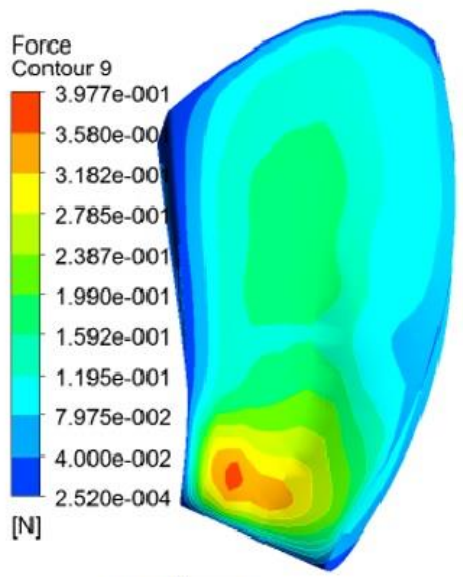

Profile "e"

Fig. 6 Meridional variations of loaded force on blade

\subsection{CFD-FEM coupling}

One-way FSI was used as the coupling strategy. Aerodynamic loades was determined by solving NavierStockes equation in the fluid and imposing the pressure distribution on to the structure. Centrifugal loads are taking to account by applying the rotor speed to the blade. Gravity loads were modeled by imposing a static load on the blade structure. The turbine blade is made of Supper alloy with young modulus of 2.15E11 $\mathrm{Pa}$ and Poisson ratio of 0.3 and density of $7913 \mathrm{~kg} / \mathrm{m}^{3}$. Von misses stresses of all cases are shown in Fig. 7. Maximum stresses are found to exist near the hub next to the trailing edge. Profile " $b$ " due to the thin trailing edge and thin max thickness had the highest stresses.
Results showed that thickening the trailing edge is more effective in decreasing the stresses in comparison with $t_{\max }$. Variations of turbine mass flow, efficiency and maximum stresses in different blade profiles are shown in Table 5. Aerodynamic efficiency decreased with thickening the blades. The place of $t_{\max }$. is more effective than decreasing thickness also leading edge thickness is the most important parameter in defining efficiency.

Profile "c" has less efficient than all profiles because of the longest $\mathrm{d}$ and the thickest $t_{\max }$.. Profile " $\mathrm{b}$ " has lower mass flow because of thicker leading edge. The best efficiency is obtained by profile " $d$ " with the thinner blade, thin leading edge, and closer place of $t_{\max }$. relative to leading edge and also thin cut off trailing edge Stress is concentrated 
in the trailing edge region, so the profiles with thicker trailing edge have lower stresses, although profile $\mathrm{c}$ is thicker than profile e but due to the thinner trailing edge illustrates higher maximum stresses. Profile " $\mathrm{d}$ " is thinner than profile "b", but because of thicker trailing edge has lower max stresses.

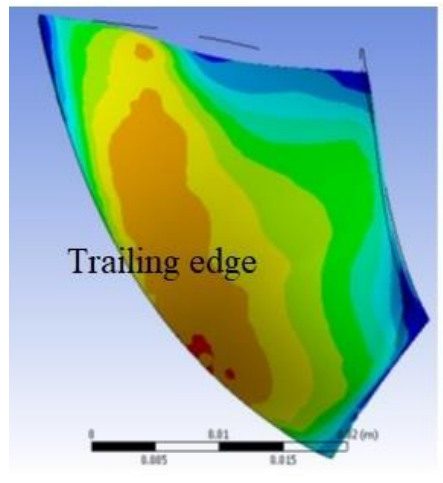

Profile a

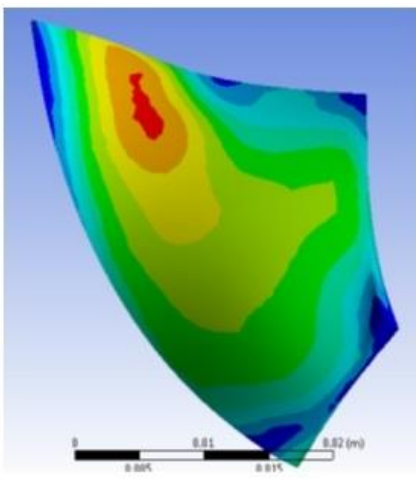

Profile b

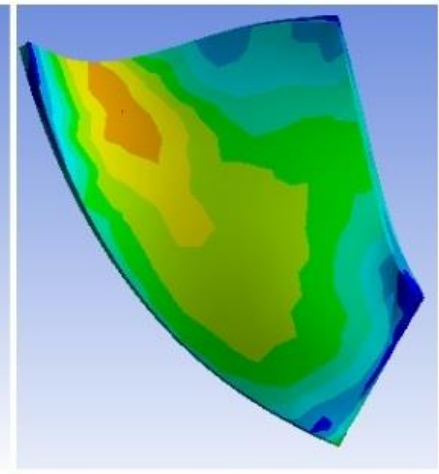

Profile c

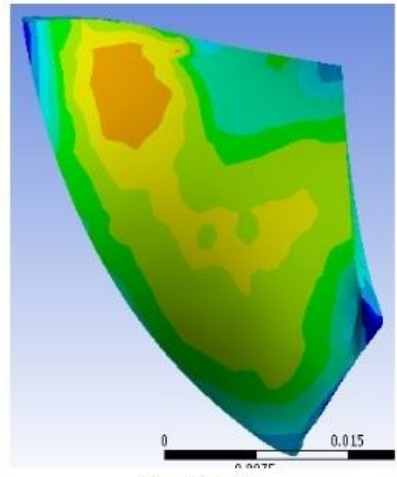

Profile d

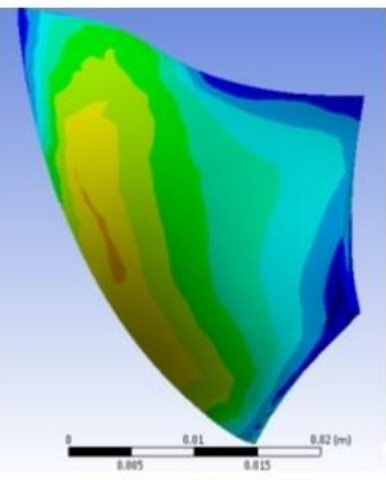

Profile e

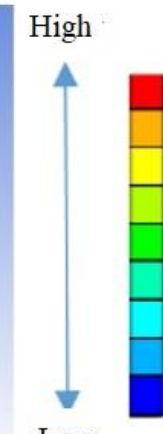

Low

Fig. 7 Von Misses stress in all the blades

Table 5

Performance characteristic of all the profiles

\begin{tabular}{|l|c|c|c|c|c|}
\hline & Profile a & Profile b & Profile c & Profile d & Profile e \\
\hline Efficiency, \% & 61.55 & 59.71 & 52.16 & 63.34 & 54.08 \\
\hline Mass flow, kg/s & 0.517 & 0.490 & 0.454 & 0.532 & 0.49 \\
\hline Maximum von Misses Stress, kPa & 619.77 & 682.44 & 563.9 & 638.77 & 552.59 \\
\hline Max. displacement, mm & 0.306 & 0.346 & 0.273 & 0.328 & 0.243 \\
\hline
\end{tabular}

\section{Conclusions}

This research investigates the thickness effects on the blade performance in double turbocharger turbine in full admission condition by a FSI model. The most effective change for rising the performance, was reducing the leading edge thickness. The best efficiency is related to a profile with thinner blade, thin leading edge, closer maximum thickness location to the leading edge and thin cut-off trailing edge. Thickening the trailing edge is more effective in decreasing the stresses compared to the $t_{\max . \text {. Also: }}$

- Thicker leading edge leads to more drop in Mach number through the bow shock.

- Higher distance of maximum thickness location from the leading edge caused the smaller separation bubble on the suction surface.

\section{References}

1. Filsinger, D.; Szwedowicz, J.; Schaefer, O. 2001. Approach to unidirectional coupled CFD-FEM analysis of axial turbocharger turbine blades, Proceedings of ASME Turbo Expo, GT-0288.

http://dx.doi.org/10.1115/1.1415035.

2. Mohammadi, N.; Fakharzadeh, M. 2017. Analysis of effect of impeller geometry including blade outlet angle on the performance of multi-pressure pumps: Simulation and experiment, Mechanika 23(1): 107-119. http://dx.doi.org/10.5755/j01.mech.23.1.17676.

3. Allali, A.; Belbachir, B.; Lousdad, A. 2016.Finite element based design of a polymer rotor of centrifugal pump Finite element based design of a polymer rotor of centrifugal pump, Mechanika 22(1): 38-43.

http://dx.doi.org/10.5755/j01.mech.22.1.12218.

4. Shanechi, M.; Odabaee, M.; Hooman, K. 2015. Optimisation of a high pressure ratio radial-inflow turbine: coupled Cfd-Fe analysis, Proceedings of ASME Turbo Expo 2015: Turbine Technical Conference and Exposition Canada. http://dx.doi.org/10.1115/GT2015-42208.

5. Vanti, F.; Pinelli, L.; Arnone, A.; Schneider, A.; Astrua, P.; Puppo, E. 2018. Aeroelastic optimization of 
an industrial compressor rotor blade geometry, Proceedings of ASME Turbo Expo, Turbomachinery Technical Conference and Exposition.

http://dx.doi.org/10.1115/GT2018-76474.

6. Chaochen, M.; Zhi, H.; Mingxu, Q. 2016. Investigation on the forced response of a radial turbine under aerodynamic excitations, Journal of Thermal Science 25(2):130-137. https://doi.org/10.1007/s11630-016-0843-1.

7. Wang, l.; Quant, R.; Kolios, A. 2016. Fluid structure interaction modelling of horizontal-axis wind turbine blades based on CFD and FEA, Journal of Wind Engineering and Industrial Aerodynamics 158: 11-25. https://doi.org/10.1016/j.jweia.2016.09.006.

8. Dai, L.; Zhou, Q.; Zhang, Y.; Yao, S.; Kang, S.; Wang, X. 2017. Analysis of wind turbine blades aeroelastic performance under yaw conditions, Journal of Wind Engineering and Industrial Aerodynamics 171: 273-287. https://doi.org/10.1016/j.jweia.2017.09.011.

9. Rafiee, R.; Tahani, M.; Moradi, M. 2016. Simulation of aeroelastic behavior in a composite wind turbine blade, Journal of Wind Engineering and Industrial Aerodynamics 151: 60-69.

https://doi.org/10.1016/j.jweia.2016.01.010.

10. Carrión, M.; Steijl, R.; Woodgate, M.; Barakos, G. N., Munduate, X., Gomez-Iradi, S. 2014. Aeroelastic analysis of wind turbines using a tightly coupled CFDCSD method, Journal of Fluids and Structures 50: 392415.

https://doi.org/10.1016/j.jfluidstructs.2014.06.029.

11. Ok Yu, D.; Kwon, J. 2014. Predicting wind turbine blade loads and aeroelastic response using a coupled CFD-CSD method, Renewable Energy 70: 184-196. https://doi.org/10.1016/j.renene.2014.03.033.

12. Filsinger, D.; Szwedowicz, J.; Schaefer, O. 2002. Approach to unidirectional coupled CFD-FEM analysis of axial turbocharger turbine blades, Journal of Turbomachinery 124(1): 125-131. https://doi.org/10.1115/1.1415035.

13. Filsinger, D.; Schaefer, O. 2003. Numerical calculation of low order blade excitation in pulse charged axial turbocharger turbines and its experimental assessment, Proceedings ASME Turbo Expo. https://doi.org/10.1115/GT2003-38182.

14. Aungier, R. H. 2005. Turbine aerodynamics, axial-flow and radial-inflow turbine design and analysis, ASME Press, New York.
15. Aungier, R. H. 2000. Centrifugal compressors: a strategy for aerodynamic design and analysis; ASME Press, New York.

16. Copeland, C. 2010. The evaluation of steady and pulsating flow performance of a double-entry turbocharger turbine; Ph.D. thesis, Imperial College of Science, Technology, and Medicine, University of London, London, UK. http://hdl.handle.net/10044/1/5635.

17. Earl Logan. 2003. Handbook of Turbo machinery. Marcel Dekker, ISBN: 0-8247-0995-0.

18. CFX 14.0. 2011 Theory guide, in ANSYS 14.0 Help.

A. Sajedin, M. H. Shojaeifard, A. Khalkhali

\section{AERO-STRUCTURAL STUDY ON THE BLADE THICKNESS EFFECTS IN AN AUTOMOTIVE TURBO- CHARGER TURBINE IN TRANSONIC CONDITIONS}

S u m m a r y

The decreasing thickness and increasing blade loading by higher twisting of turbine blades introduces considerable aeroelastic effects, which are caused by FSI (fluid structure interaction). In this study, an FSI model for a turbocharger turbine blades at full scale is established. The aerodynamic loads are calculated using a CFD model, and the blade structural responses are determined using a FEA model. The interface of CFD and FEA is based on a oneway coupling. Validation is performed by reference to experimental data carried out on this turbocharger turbine. Maximum stresses and tip deflections for five different distribution case are found to be within material and structural limits, according to relevant design standards under transonic conditions.

Keywords: fluid structure, blade thickness, turbocharger, shock.

Received January 05, 2019

Accepted April 25, 2019 